\title{
HER2 testing of gynecologic carcinosarcomas: tumor stratification for potential targeted therapy
}

\author{
Douglas Rottmann ${ }^{1} \cdot$ Olivia L. Snir ${ }^{2} \cdot$ Xinyu $\mathrm{Wu}^{1} \cdot$ Serena Wong ${ }^{1} \cdot$ Pei Hui ${ }^{1} \cdot$ Alessandro D. Santin $^{3} \cdot$ Natalia Buza $^{1}$
}

Received: 22 June 2019 / Revised: 30 July 2019 / Accepted: 31 July 2019 / Published online: 2 September 2019

(c) United States \& Canadian Academy of Pathology 2019

\begin{abstract}
A recent phase II clinical trial showed increased progression-free survival in patients with HER2-positive endometrial serous carcinoma receiving trastuzumab in addition to carboplatin-paclitaxel chemotherapy. Similar to endometrial serous carcinomas, carcinosarcomas of the female genital tract have a dismal prognosis and could potentially benefit from new targeted therapeutic approaches. We aimed to systematically evaluate the characteristics of HER2 expression/amplification in gynecologic carcinosarcomas using standardized staining methods and scoring criteria. Tumors from 80 patients (65 uterine, 15 tubo-ovarian) were included, containing a serous $(60 \%)$, endometrioid (10\%), clear cell (3\%), undifferentiated (3\%), neuroendocrine (1\%), or mixed (24\%) carcinoma, and either a homologous $(46 \%)$, or a heterologous (54\%) sarcoma component. HER2 scores were assigned to both components per the 2007 and 2013 ASCO/CAP breast scoring criteria. A total of 13 cases (12 uterine, 1 ovarian, 16\%) were HER2 positive (either by immunohistochemistry or FISH) using the 2013 criteria, while only 10 cases ( 9 uterine, 1 ovarian, 13\%) were HER2 positive per the 2007 criteria. Nine cases showed a change in their HER2 immunohistochemical score between the two scoring systems, including two cases with a change in the overall HER2 status from negative (2007) to positive (2013). Heterogeneity of HER2 protein expression was observed in $38 \%$ of HER2-positive tumors, and a lateral/basolateral membranous staining pattern was common. The sarcoma component showed 2+, equivocal HER2 expression in five cases, one of which also demonstrated HER2 amplification by FISH. All HER2-positive carcinosarcomas had either a serous or a mixed carcinoma component, and all but one HER2-positive tumors were of uterine primaries. Our study demonstrates that gynecologic carcinosarcomas share similarities in their HER2 expression/amplification profiles to endometrial serous carcinomas, which should be taken into account when assessing their HER2 status to ensure appropriate patient selection for potential targeted HER2-based therapies in the future.
\end{abstract}

Supplementary information The online version of this article (https:// doi.org/10.1038/s41379-019-0358-x) contains supplementary material, which is available to authorized users.

$\triangle$ Natalia Buza

natalia.buza@yale.edu

1 Department of Pathology, Yale School of Medicine, New Haven, CT, USA

2 Department of Pathology, Oregon Health \& Science University, Portland, OR, USA

3 Department of Obstetrics, Gynecology, and Reproductive Sciences, Division of Gynecologic Oncology, Yale School of Medicine, New Haven, CT, USA

\section{Introduction}

Carcinosarcoma (malignant mixed Müllerian tumor) of the gynecologic tract is a rare, highly aggressive malignant neoplasm. Patients typically present in their seventh or eighth decade with pelvic pain, vaginal bleeding, and uterine enlargement [1]. Uterine carcinosarcomas comprise an increasing number of primary endometrial malignancies, rising from $2 \%$ in 1973 to $6 \%$ in 2013, and they represent an even greater share of uterine cancer deaths at $16 \%[2,3]$. Ovarian carcinosarcomas account for $1-3 \%$ of all ovarian malignancies [4]. Myometrial invasion (in uterine carcinosarcoma) and lymphovascular invasion (in both uterine and ovarian carcinosarcoma) are common at the time of diagnosis, and even clinical stage I tumors have been shown to have lymph node metastasis in up to $60 \%$ of cases [4]. Up to $35 \%$ of uterine and $90 \%$ of ovarian carcinosarcoma have spread to other organs at the time of diagnosis, and the 
recurrence rate exceeds $40 \%[5,6]$. The prognosis of both uterine and ovarian carcinosarcoma is dismal, with an overall 5-year survival rate of less than $30 \%[4,7]$.

The primary therapy for both uterine and ovarian carcinosarcoma is debulking (cytoreductive) surgery with or without adjuvant chemotherapy [8]. Chemotherapy may include an ifosfamide-based regimen [9, 10], or a combination of paclitaxel and carboplatin, which has recently been found to result in similar overall survival and improved progression-free survival compared with paclitaxel-ifosfamide in uterine and ovarian carcinosarcomas [11]. However, given the limited effect of current chemotherapy regimens in advanced stage carcinosarcoma and the significant proportion of patients who present at an advanced stage, it is of considerable interest to explore additional methods of treatment.

The majority of carcinosarcomas harbor a serous carcinoma component (either in a pure form or as part of a mixed carcinoma component), and the metastatic or recurrent tumor frequently consists of carcinoma only, suggesting that the serous carcinoma element may dictate the clinical behavior of many gynecological carcinosarcomas. HER2 overexpression/amplification has been previously reported in $35 \%$ of endometrial serous carcinomas following the 2007 American Society of Clinical Oncology/College of American Pathologists (ASCO/CAP) scoring guidelines [12] and a recent phase II clinical trial showed an increase in progression-free survival in patients with HER2-positive endometrial serous carcinoma when trastuzumab was used in combination with chemotherapy over chemotherapy alone [13]. In addition, in vitro and in vivo studies have also demonstrated antitumor activity of HER2-targeted therapies in ovarian and uterine carcinosarcomas [14-16]. The current study aimed to perform a comprehensive analysis of HER2 status-protein expression by immunohistochemistry and gene amplification by fluorescent in situ hybridization (FISH) - and comparison of different scoring criteria in a large cohort of gynecologic carcinosarcomas, in hopes to aid patient selection for potential future targeted anti-HER2 treatment regimens for these biologically aggressive tumors.

\section{Materials and methods}

The study was approved by the Institutional Review Board. A text search of the pathology departmental archives at Yale New Haven Hospital was performed using the keywords "carcinosarcoma" and "malignant mixed Müllerian tumor", and all carcinosarcomas of the female reproductive tract with available HER2 status were retrieved for the study. A total of 80 cases were identified. Patient demographics, tumor stage, and detailed FISH results were gathered from the pathology reports. Patient follow-up information was retrieved from the electronic medical records. HER2 antibody clone EP3 (Epitomics/Abcam) was used at 1:250 dilution for immunohistochemistry, and PathVysion (Abbott) Kit was employed for HER2 FISH. All available hematoxylin and eosin stained slides were reviewed for each case to confirm the diagnosis, primary site, and the histologic subtypes of carcinoma and sarcoma components. HER2-stained slides were then reviewed systematically, and both the carcinoma and when present, the sarcoma components were scored according to both the 2007 and 2013 ASCO/CAP guidelines for breast carcinoma by two of the authors (DR, NB) (Table 1) [17, 18]. HER2-immunostained slides were also evaluated for the presence or absence of significant intratumoral heterogeneity, defined as a twopoint or greater difference in the HER2 scores between areas of the tumor. Fisher's exact test was used to analyze the correlation between tumor characteristics and HER2 status. Overall survival was estimated by the Kaplan-Meier method and assessed by log-rank test. SAS ${ }^{\oplus}$ version 9.4 was used for the analyses. $P$ values of $<0.05$ were considered statistically significant.

\section{Results}

Carcinosarcomas from 80 patients were included, with 65 carcinosarcomas of uterine and 15 of tubo-ovarian origin. Patients ranged in age from 48 to 87 years, with an average age of 67 years (median 67 years). The carcinomatous component was most commonly pure serous $(60 \%)$, mixed (24\%), or pure endometrioid (10\%). Among ovarian/fallopian tube cases $87 \%$ had a high-grade serous carcinoma component, while among uterine carcinosarcomas only $54 \%$ showed a pure serous carcinoma component and $29 \%$ a mixed carcinoma (Table 2). The majority of mixed carcinomas contained a serous carcinoma component (16 of 19 cases). The sarcomatous component was homologous in $46 \%$ of all cases and contained heterologous elements (either pure heterologous or both homologous and heterologous) in 54\% of all tumors, with the most common heterologous components being rhabdomyosarcoma $(60 \%$ of sarcomas with heterologous elements, $33 \%$ of total cases) and chondrosarcoma $(58 \%, 31 \%)$. Other heterologous sarcomatous elements, namely liposarcoma and osteosarcoma were rare, appearing in only four cases $(9 \%$ and $5 \%$ respectively) and always in combination with either rhabdomyosarcoma or chondrosarcoma. Ovarian tumors were more likely to contain a chondrosarcoma element: $53 \%$ of ovarian carcinosarcomas showed some chondroid differentiation, compared with only $26 \%$ of uterine tumors. Table 2 contains a detailed breakdown of the carcinomatous and sarcomatous components of the study cases. 
Table 1 HER2 immunohistochemistry and FISH scoring criteria

\begin{tabular}{|c|c|c|c|}
\hline \multicolumn{2}{|c|}{ Scoring Criteria } & \multirow{2}{*}{$\begin{array}{l}2007 \text { ASCO/CAP for breast cancer } \\
\text { No staining }\end{array}$} & \multirow{2}{*}{$\begin{array}{l}2013 \text { ASCO/CAP for breast cancer } \\
\text { No staining OR membrane staining that is incomplete } \\
\text { and faint/barely perceptible in } \leq 10 \% \text { of tumor cells }\end{array}$} \\
\hline IHC & 0 & & \\
\hline & $1+$ & $\begin{array}{l}\text { Weak, incomplete membrane staining in any } \\
\text { proportion of tumor cells }\end{array}$ & $\begin{array}{l}\text { Incomplete membrane staining that is faint/barely } \\
\text { perceptible in }>10 \% \text { of tumor cells }\end{array}$ \\
\hline & $2+$ & $\begin{array}{l}\text { Complete membrane staining that is either } \\
\text { nonuniform or weak but with obvious } \\
\text { circumferential distribution in at least } 10 \% \text { of cells } \\
\text { OR intense, complete membrane staining in }<30 \% \text { of } \\
\text { invasive tumor cells }\end{array}$ & $\begin{array}{l}\text { Circumferential membrane staining that is incomplete } \\
\text { and/or weak/moderate and within }>10 \% \text { of invasive } \\
\text { tumor cells OR complete and intense circumferential } \\
\text { membrane staining in } \leq 10 \% \text { of invasive tumor cells }\end{array}$ \\
\hline & $3+$ & $\begin{array}{l}\text { Uniform intense membrane staining of }>30 \% \text { of } \\
\text { invasive tumor cells }\end{array}$ & $\begin{array}{l}\text { Complete, intense circumferential staining in }>10 \% \\
\text { of invasive tumor cells }\end{array}$ \\
\hline \multirow[t]{3}{*}{ FISH } & Negative & $\begin{array}{l}\text { HER2/CEP17 ratio }<1.8 \text {; average HER2 gene copy } \\
\text { number }<4.0\end{array}$ & $\begin{array}{l}\text { HER } 2 \text { copy number }<4.0 \text { signals/cell AND, if dual } \\
\text { probe, } \text { HER } 2 / C E P 17 \text { ratio }<2.0\end{array}$ \\
\hline & Equivocal & $\begin{array}{l}\text { HER2/CEP17 ratio between } 1.8 \text { and } 2.2 \text { OR average } \\
\text { HER2 gene copy number between } 4.0 \text { and } 6.0\end{array}$ & $\begin{array}{l}\text { HER } 2 \text { copy number } \geq 4.0 \text { and }<6.0 \text { signals/cell AND, } \\
\text { if dual probe, HER } 2 / C E P 17 \text { ratio }<2.0\end{array}$ \\
\hline & Positive & $\begin{array}{l}\text { Average of }>6 \text { HER } 2 \text { gene copies/nucleus OR } \\
\text { HER2/CEP17 ratio }>2.2\end{array}$ & $\begin{array}{l}\text { HER } 2 \text { copy number } \geq 6.0 \text { signals/cell OR HER } 2 / \\
\text { CEP17 ratio } \geq 2.0 \text {, regardless of HER } 2 \text { copy number }\end{array}$ \\
\hline
\end{tabular}

ASCO American Society of Clinical Oncology, CAP College of American Pathologists, IHC immunohistochemistry, FISH fluorescent in situ hybridization

Table 2 Tumor histological characteristics

\begin{tabular}{llcl}
\hline Primary tumor site & & $\begin{array}{l}\text { Uterine } \\
(n=65)\end{array}$ & $\begin{array}{l}\text { Ovarian } \\
(n=15)\end{array}$ \\
\hline $\begin{array}{l}\text { Carcinoma } \\
\text { histologic subtype }\end{array}$ & Serous & $35(54 \%)$ & $13(87 \%)$ \\
& Endometrioid & $7(11 \%)$ & $1(7 \%)$ \\
& Clear cell & $2(3 \%)$ & 0 \\
& Neuroendocrine & $1(2 \%)$ & 0 \\
& Undifferentiated & $1(2 \%)$ & $1(7 \%)$ \\
& Mixed & $19(29 \%)$ & 0 \\
Sarcoma histologic & Homologous & $34(52 \%)$ & $3(20 \%)$ \\
subtype & Heterologous & $31(48 \%)$ & $12(80 \%)$ \\
\hline
\end{tabular}

Using the 2013 ASCO/CAP criteria 13 cases (12 uterine and 1 ovarian, 13/80,16\%) were positive for HER2 in the carcinomatous component either by immunohistochemistry and/or FISH, while only ten cases (nine uterine, one ovarian, 10/80, 13\%) were HER2 positive by the 2007 criteria (Tables 3 and 4) (Figs. 1 and 2). The HER2 positivity rate was higher among uterine primaries (14\% per 2007 and $19 \%$ per 2013 scoring criteria) compared with ovarian primaries (7\% per both scoring criteria). All of the HER2positive tumors had either a serous or a mixed carcinomatous component, while all tumors with endometrioid, clear cell, undifferentiated, or neuroendocrine carcinoma subtype were HER 2 negative $(p<0.005)$. The HER 2 positivity rate among tumors with serous and mixed carcinoma components was 15\% (10/67) and 19\% (13/67) using the 2007 and 2013 scoring criteria, respectively. Among the 19 uterine carcinosarcomas with a mixed carcinoma, 16 tumors contained a serous carcinoma component, 4 of which (4 of 16, 25\%) were HER2 positive. The remaining three tumors containing mixed clear cell and endometrioid carcinoma components were all HER2 negative.

Nine cases showed discrepancy in their carcinoma HER2 immunohistochemical score between the two sets of criteria; seven cases changed from 1+ (2007) to 0 (2013) and two cases from $2+$ (2007) to $3+$ (2013). Both of the latter cases had nonamplified FISH, and thus the change in criteria represented a change in HER2 status from negative (2007) to positive (2013). There were no differences in the immunohistochemical score among the sarcoma components, regardless of the guidelines used. Significant intratumoral heterogeneity of HER2 staining was appreciated in 20 cases-25\% of all cases, and 38\% of HER2-positive tumors (Fig. 3a, b). Incomplete—basal or basolateral ("Ushaped")-staining pattern was commonly observed among the HER2-positive tumors (Fig. 3c, d).

The sarcomatous component was present on the HER2stained slide in 44 cases (55\%), 5 of which (11\%) showed 2 + HER2 immunohistochemical expression by both 2007 and 2013 scoring criteria. No 3+ staining was observed in the sarcomatous component of any case. Two of the five tumors with $2+$ staining in the sarcoma had only $1+$ HER2 score (by both scoring criteria) in their carcinoma components. FISH performed on sarcoma components with $2+$ immunohistochemical score revealed one case with an HER2/CEP17 ratio of 2.0, average HER2 copy number of 4.2/cell (equivocal amplification per ASCO/CAP 2007, positive per ASCO/CAP 2013) (Fig. 4), the remaining four cases showed no HER2 amplification. 
Table 3 HER2

immunohistochemical score distribution and HER2 FISH results

\begin{tabular}{|c|c|c|c|}
\hline $\begin{array}{l}\text { HER2 IHC Score } \\
\text { ASCO/CAP } 2007\end{array}$ & $\begin{array}{l}\text { Carcinoma component } \\
\text { (total } n=80 \text { ) }\end{array}$ & $\begin{array}{l}\text { Sarcoma component } \\
\text { (total } n=44 \text { ) }\end{array}$ & $\begin{array}{l}\text { FISH amplification per } 2007 \\
\text { ASCO/CAP criteria ( } \mathrm{n} \\
\text { positive/N performed) }\end{array}$ \\
\hline 0 & 20 uterine, 1 ovarian & 22 uterine, 9 ovarian & $0 / 0$ \\
\hline $1+$ & 19 uterine, 6 ovarian & 6 uterine, 2 ovarian & $0 / 2$ \\
\hline $2+$ & 20 uterine, 8 ovarian & 5 uterine, 0 ovarian & $5 / 28$ \\
\hline $3+$ & 6 uterine, 0 ovarian & 0 uterine, 0 ovarian & $1 / 2$ \\
\hline $\begin{array}{l}\text { HER2 IHC Score } \\
\text { ASCO/CAP } 2013\end{array}$ & $\begin{array}{l}\text { Carcinoma } \\
\text { component (total } \\
n=80)\end{array}$ & $\begin{array}{l}\text { Sarcoma component } \\
\text { (total } n=44)\end{array}$ & $\begin{array}{l}\text { FISH amplification per } \\
2013 \text { ASCO/CAP criteria } \\
\text { (n positive/N performed) }\end{array}$ \\
\hline 0 & 25 uterine, 3 ovarian & 22 uterine, 9 ovarian & $0 / 0$ \\
\hline $1+$ & 14 uterine, 4 ovarian & 6 uterine, 2 ovarian & $0 / 2$ \\
\hline $2+$ & 18 uterine, 8 ovarian & 5 uterine, 0 ovarian & $5 / 26$ \\
\hline $3+$ & 8 uterine, 0 ovarian & 0 uterine, 0 ovarian & $1 / 4$ \\
\hline
\end{tabular}

IHC immunohistochemistry, FISH fluorescent in situ hybridization, ASCO American Society of Clinical Oncology, CAP College of American Pathologists
In five cases the HER2 status was evaluated in both the primary (four uterine, one ovarian) tumor and a metastasis, all of which demonstrated a change in the HER2 immunohistochemical score (Table 5). In four of the five cases the overall HER2 status did not change, and in one case the primary ovarian tumor was HER2 $2+$ on immunohistochemistry and was not amplified (per 2007 criteria) or equivocal (per 2013 criteria) by FISH, while the metastatic tumor was HER2 amplified by FISH according to the 2013 criteria (equivocal per the 2007 criteria) (Table 5).

Follow-up information was available for 79 patients (64 uterine and 15 ovarian primaries), and the follow-up period ranged between 1 and 63 months (median: 23 months) (Table 6).

Overall survival rates were compared between HER2 positive and HER2-negative uterine carcinosarcomas (Supplementary Fig. 1). Log-rank test did not reveal a statistically significant difference between the two groups $(p=$ 0.8023). Due to only one HER2 positive case among ovarian carcinosarcomas, survival analysis was not performed in these patients.

\section{Discussion}

Carcinosarcomas of the female reproductive tract are composed of a carcinoma and a sarcoma component, which may resemble native uterine sarcomas, i.e. leiomyosarcoma, endometrial stromal sarcoma, fibrosarcoma, or it may show heterologous differentiation, such as rhabdomyosarcoma, chondrosarcoma, osteosarcoma, or liposarcoma. The epithelial component of carcinosarcomas most commonly consists of serous carcinoma, either in a pure form or mixed with other carcinoma types. Most patients already have advanced stage disease at the time of presentation, with the metastatic tumor only composed of the serous carcinoma component in many cases. Similarly, to advanced stage serous carcinoma of either endometrial or ovarian primary, traditional surgical debulking and chemotherapy only have a limited effect on the prognosis of carcinosarcomas. The recurrence rate is high and the median survival is only 16-40 months for uterine, and 8-32 months for ovarian carcinosarcoma [5, 19-21]. In the era of precision medicine there is an unmet need for targeted therapies against these aggressive malignancies.

Molecular studies suggest, that despite the histopathologic diversity inherent to carcinosarcomas, they are predominately monoclonal, arising from the carcinoma component through epithelial-mesenchymal transition [22-25]. Uterine and ovarian carcinosarcomas share many of the genetic abnormalities present in endometrial serous and endometrioid carcinomas, and in high-grade ovarian serous carcinomas, respectively [26]. Mutations in $K R A S$, PIK3CA, CTNNB1, PTEN, FBXW7, TP53, ARIDIA, RB1, CHD4, CSMD3, FBXW7, PPP2RIA, and BCOR have been previously reported [26-30], and more recent whole exome sequencing analysis identified mutations in histone genes $H 2 A$ and $H 2 B$ and implicated their role in epithelial-mesenchymal transition [31]. In addition, amplification of $c-M y c$, and TERT have also been identified in both ovarian and uterine carcinosarcoma [31-34].

HER2 gene amplification/protein overexpression has been found in variable proportion of uterine carcinosarcomas, ranging between 3 and $56 \%$ in the largest series, using various different interpretation and scoring criteria [33, 35-39]. In most studies HER2 overexpression was reported to be less frequent in the sarcoma component, with the highest rate of $29 \%$, although both $2+$ and $3+$ scores were interpreted as HER2 positive in the latter study [35]. 


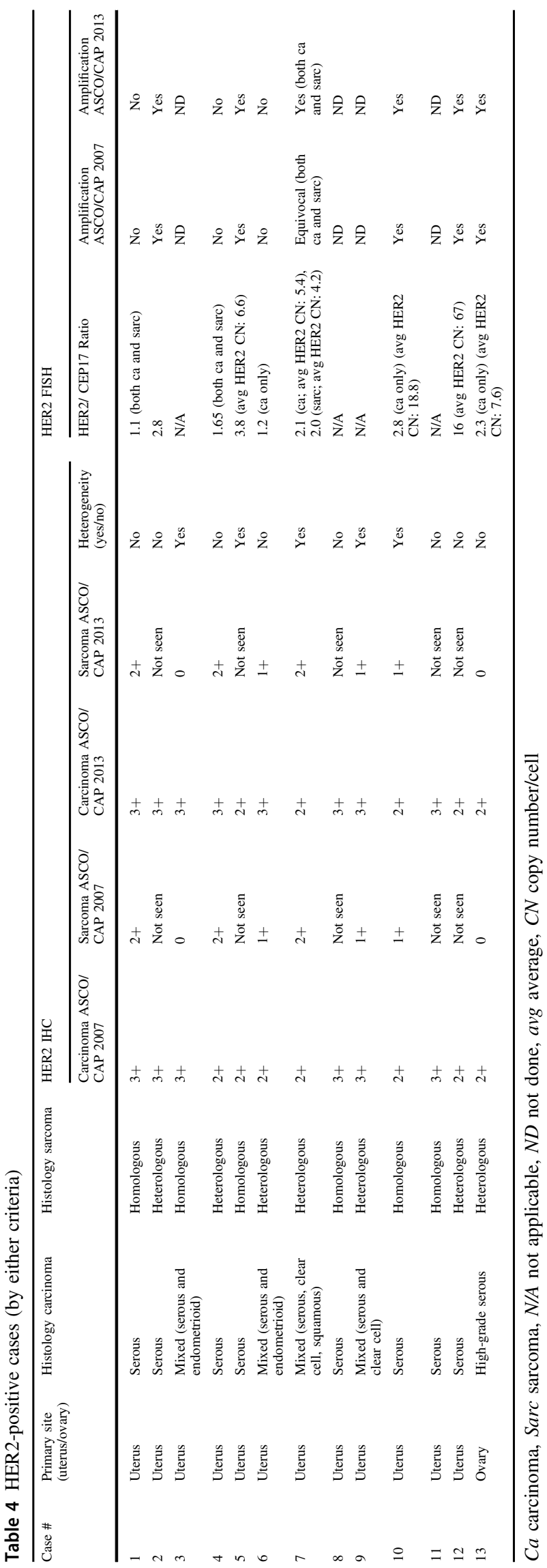

Only a handful of ovarian carcinosarcomas have been previously evaluated for their HER2 status and none of them were found to have HER2 amplification or overexpression [40]. Similarly, HER2 positivity is uncommon in ovarian high-grade serous carcinomas, with 0-3\% HER2 amplification/overexpression rate in most studies [40-42], and 11 $\%$ HER 2 protein overexpression (including both $2+$ and $3+$ scores) in a prior Gynecologic Oncology Group trial [43]. In contrast, approximately one third of endometrial serous carcinomas are HER2 positive (by either immunohistochemistry, or FISH, or both) [12], and a recently published clinical trial reported improved progression-free survival when trastuzumab was added to the chemotherapy regimen in patients with HER2-positive endometrial serous carcinoma [13]. Promising results were also reported in preclinical in vitro and in vivo studies on uterine and ovarian carcinosarcoma cell lines with HER2 protein overexpression using anti-HER2 antibody-drug conjugates SYD985 and T-DM1, and small molecule tyrosine kinase inhibitor neratinib [14-16]. SYD985 also induced significant bystander killing of HER2-negative tumor cells (scores 0/1+) when admixed with HER2-positive tumor cells (score 3+), suggesting that SYD985 may be effective in tumors with heterogeneous HER2 expression and in carcinosarcomas with an HER2-negative sarcoma component [14].

We performed a comprehensive analysis of HER2 protein expression and amplification in a large cohort of uterine and ovarian carcinosarcomas comparing different scoring criteria, in order to better understand the specific characteristics of HER2 staining and its correlation with gene amplification to help guide future clinical studies in these rare, aggressive tumors. HER2 overexpression and/or amplification was observed in $16 \%$ of our cases (13/80) using the 2013 ASCO/CAP breast scoring criteria and in $13 \%$ of tumors (10/80) with the 2007 ASCO/CAP breast scoring criteria, a significantly lower rate compared with our previously published results on endometrial serous carcinomas [12]. More importantly, all HER2-positive cases had a serous carcinoma component (pure or mixed with other histologic subtypes), while none of the tumors with endometrioid or other nonserous carcinoma subtypes showed HER2 overexpression or amplification. In addition, a significant difference was observed regarding the primary tumor site: only one ovarian carcinosarcoma was HER2 positive (1 of 15 tumors), the remaining HER2-positive cases were all uterine primaries. HER2 overexpression/ amplification was identified in the carcinoma component only in the majority of HER2-positive cases. The sarcoma component demonstrated equivocal $(2+)$ HER2 expression in five tumors, only one of which was amplified by FISH (ratio:2.0, HER2 copy number: 4.2/cell) with identical HER2 expression and amplification results in the 
Fig. 1 Uterine carcinosarcoma (case \#1, Table 4) with serous carcinoma and homologous (a) and heterologous,

chondrosarcomatous (b) sarcoma components. HER2 immunohistochemical score was $3+$ in the carcinoma component and $2+$ in the sarcoma component $(\mathbf{c}, \mathbf{d})$
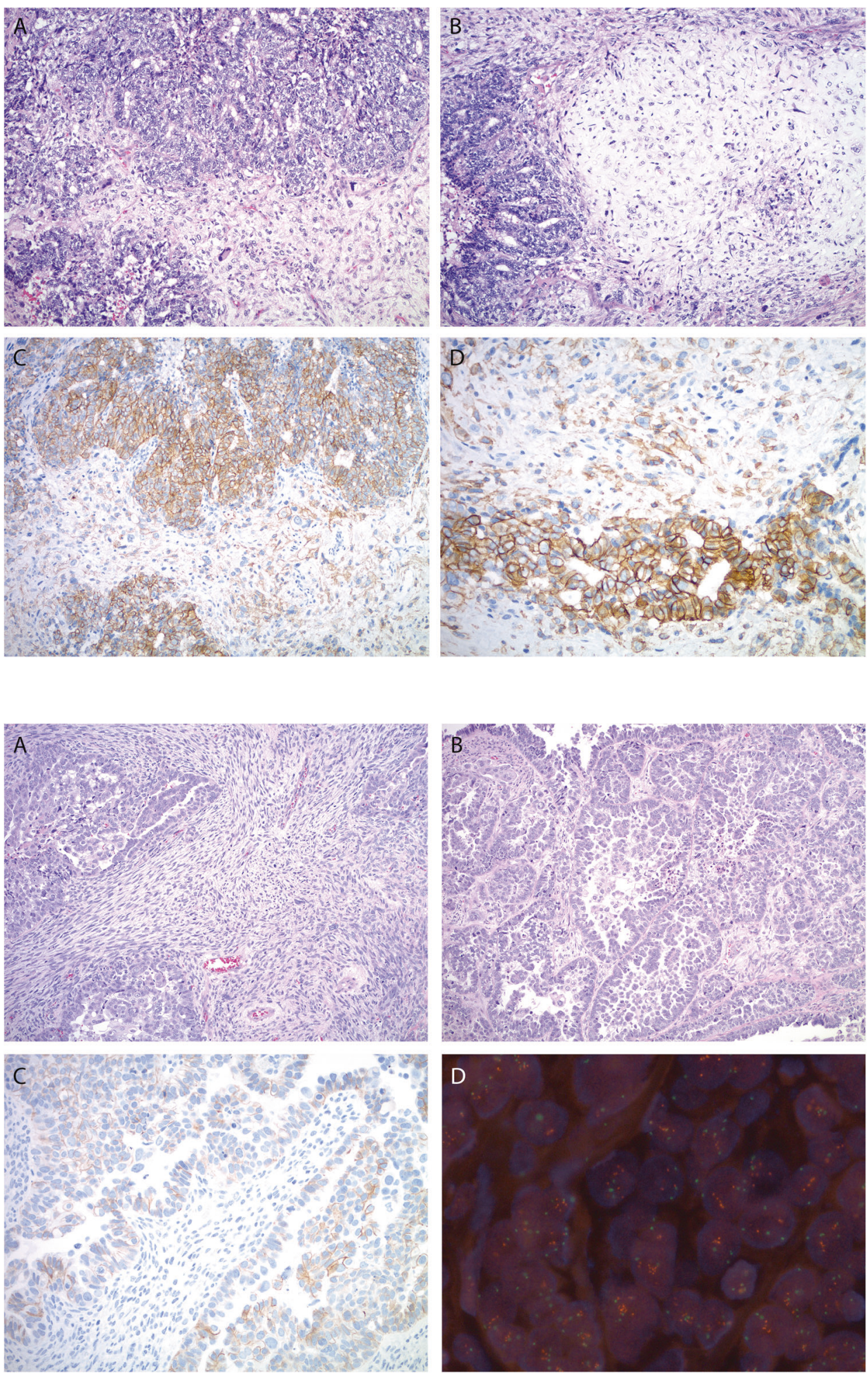

Fig. 2 Ovarian carcinosarcoma (case \#13, Table 4) with highgrade serous carcinoma and homologous sarcoma components (a, b). HER2 immunostain showed weak to moderate membranous staining in a lateral/basolateral pattern (2 + score) in the carcinoma component (c), and HER2 amplification was detected by FISH $($ HER $2 / C E P 17$ ratio $=$ 2.3) (d)

corresponding carcinoma component. Similar to our prior observation in endometrial serous carcinomas and previous reports on gastric carcinomas [12, 44-46], significant intratumoral heterogeneity was seen in more than a third of HER2-positive carcinosarcomas, and a basal/basolateral incomplete membranous staining pattern was also common. Our prior study comparing the 1998 Food and Drug Administration and 2007 ASCO/CAP breast criteria in endometrial serous carcinoma showed better concordance between HER2 immunohistochemistry and FISH when the 
Fig. 3 Uterine carcinosarcoma (case \#9, Table 4) with marked intratumoral heterogeneity of HER2 immunostaining in the serous carcinoma component (a b). Lack of apical HER2 immunostaining was frequently observed in carcinosarcomas resulting in a lateral/basolateral staining pattern (c: case \#8, Table 4, d: case \#2, Table 4)
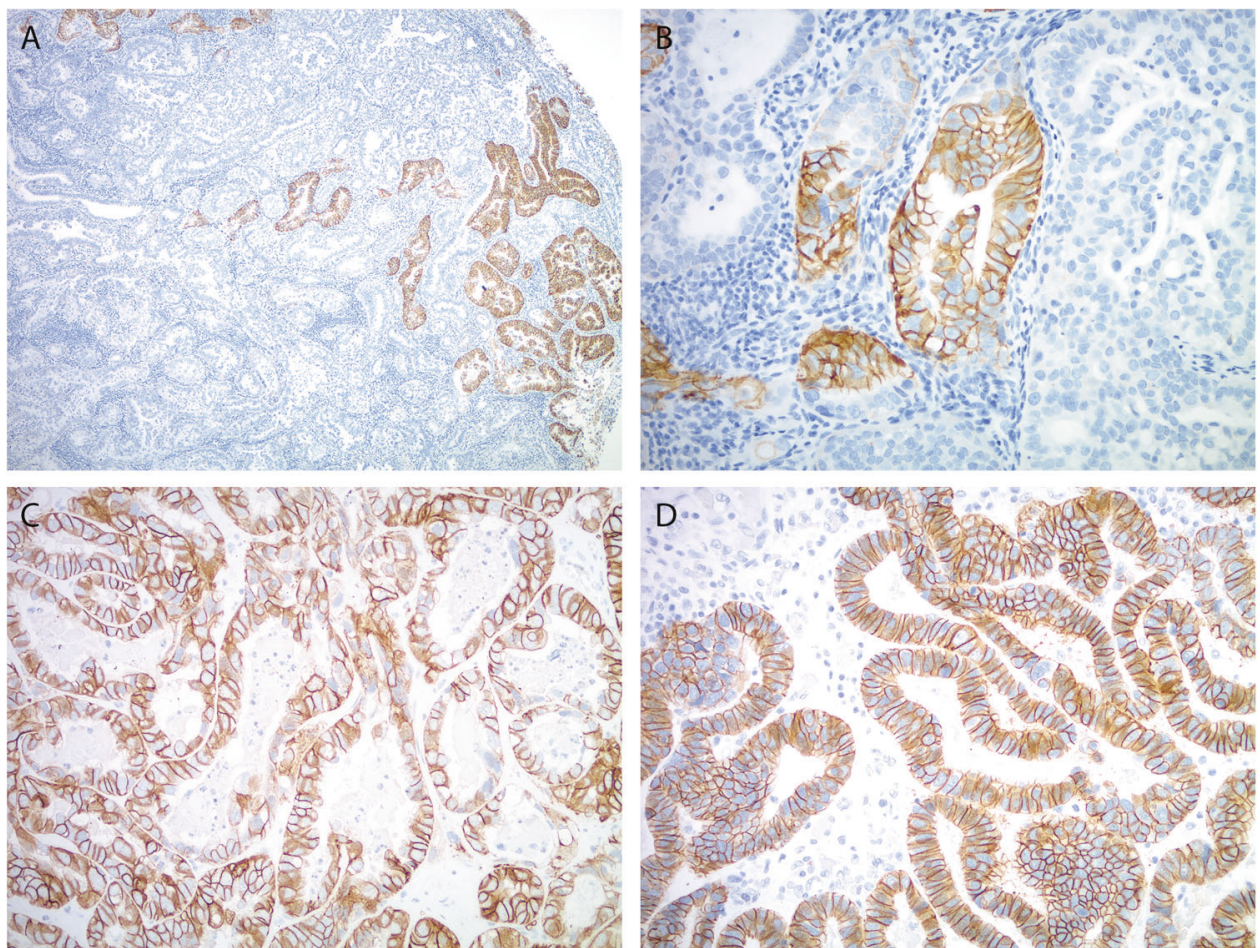

2007 scoring criteria were used ( $75 \%$ vs. $81 \%$, respectively) [12]. In the current study FISH was performed on all HER2 immunohistochemistry $2+$ cases, but only a small number of $1+$ and $3+$ cases $(n=6)$ were tested for HER 2 amplification, not sufficient for a meaningful analysis of immunohistochemistry/FISH concordance.

A new set of HER2 testing guidelines for breast cancer have been published by the ASCO/CAP in 2018 to address recommendations for some less common HER2 FISH assay results [47]. Given the HER2 testing algorithm employed in our study-immunohistochemistry, followed by FISH on $2+$ cases - the only potential change in the HER 2 status from the ASCO/CAP 2013 scoring criteria would affect immunohistochemistry $2+$ cases with a FISH HER2/CEP17 ratio of $<$ 2.0 and an average of $\geq 4.0$ and $<6.0$ HER 2 signals per cell, or a FISH ratio of $\geq 2.0$ and an average of $<4.0$ HER 2 signals per cell. All five cases with an HER2 immunohistochemical score of $2+$ per the ASCO/CAP 2013 criteria (cases \#5, 7 10, 12 , and 13 in Table 4) showed a FISH ratio of $\geq 2.0$ and $\geq 4.0$ HER2 signals per cell, therefore would have also been positive using the 2018 ASCO/CAP criteria.

Comparison of HER2 status between primary and metastatic endometrial carcinomas has been previously reported in a large tissue microarray-based study and found a discrepant HER2 immunohistochemical score $(0-2+$ vs. 3 + ) in $23 \%$ of cases [48]. In most of these cases the primary HER2-positive tumor became HER2 negative in the metastasis, but a reverse change (HER2-negative primary to HER2-positive metastasis) was also observed [48]. Our study also included a small number of paired primary and metastatic carcinosarcomas, all of which showed a difference in their HER2 immunohistochemical score. However, the overall HER2 status only changed in one tumor (one of five) from equivocal in the primary to positive (amplified by FISH) in the metastasis per the 2013 ASCO/CAP criteria. Of note, the same metastatic tumor would have been equivocal per the 2007 ASCO/CAP criteria and negative per the 2018 ASCO/CAP criteria.

In conclusion, we identified HER2 overexpression/ amplification in up to $16 \%$ of gynecologic carcinosarcomas. Characteristics of HER2 protein expression were similar to those of previously reported in gastric and in endometrial serous carcinomas with marked intratumoral heterogeneity and frequent lack of apical staining. Notably, only tumors with a serous carcinoma component were HER2 positive, and all but one HER2-positive tumors were of uterine primaries. Adding evaluation of HER2 expression/amplification in the sarcoma component did not change the overall HER2 status from negative to positive in any of the cases. Based on the similarities of HER2 expression identified in the current study, the HER2 testing and scoring approach previously recommended for endometrial serous carcinomas and used in the recent clinical trial $[12,13]$ could be applied to carcinosarcomas: the 2007 ASCO/CAP breast scoring criteria with specific modifications to account for frequent lack of apical staining and intratumoral heterogeneity. A large tumor section should be selected for both immunohistochemistry and FISH $\left(\geq 1 \mathrm{~cm}^{2}\right.$ area of tumor), 
Fig. 4 Uterine carcinosarcoma (case \#7, Table 4) composed of serous carcinoma (a) and heterologous,

rhabdomyosarcomatous (b) elements. HER2

immunostaining score was $2+$ in both the carcinoma (c) and sarcoma (d) components. The HER2/CEP17 ratio by FISH was 2.1 in the carcinoma component (e) and 2.0 in the sarcoma component (f)
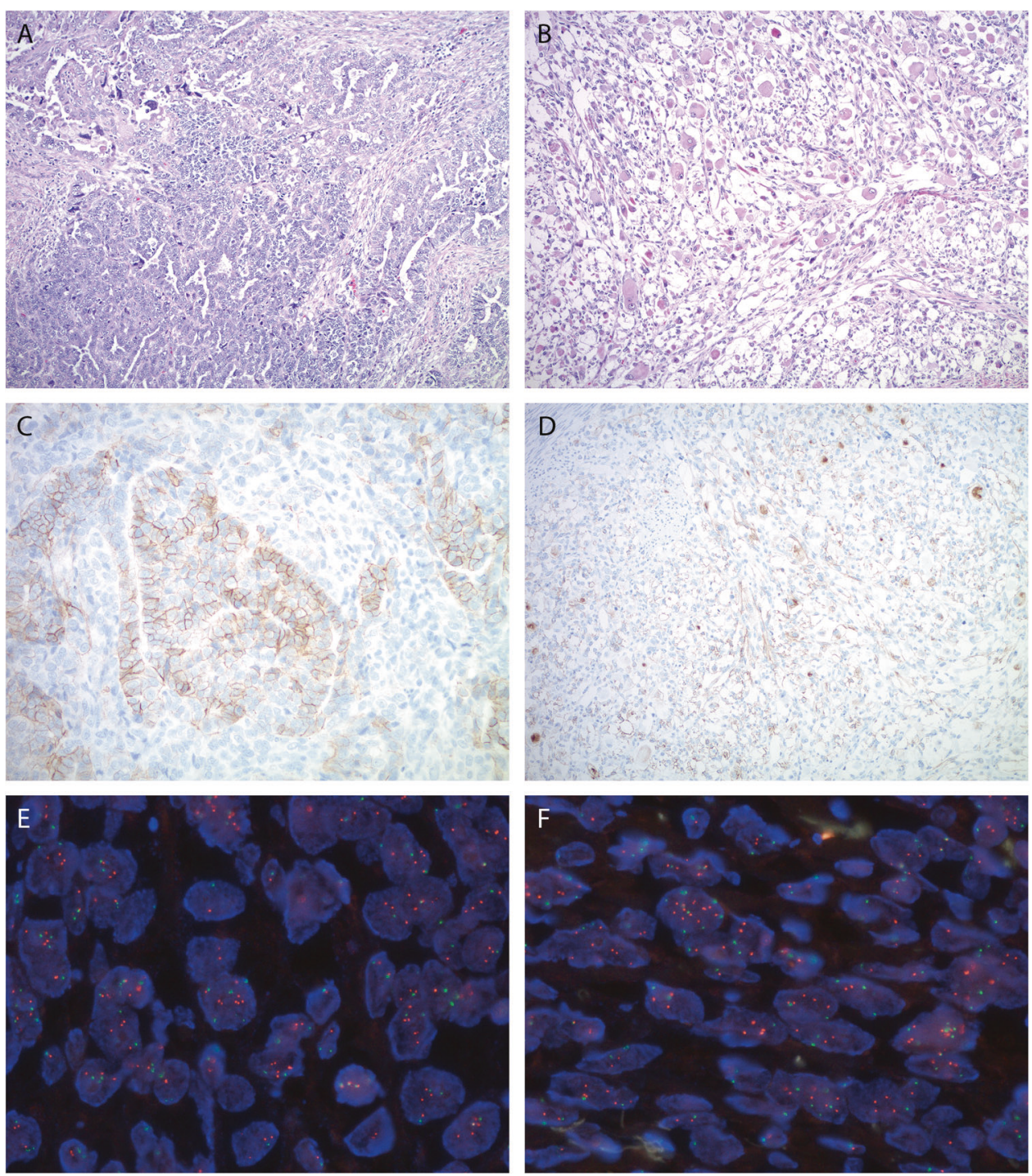
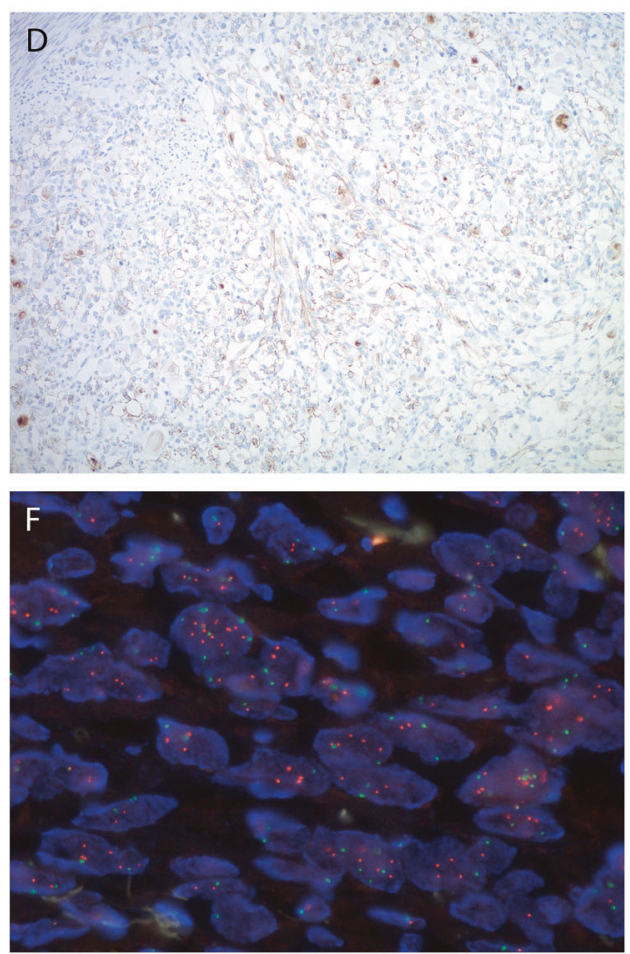

Table 5 HER2 IHC and FISH in paired primary and metastatic tumors

\begin{tabular}{|c|c|c|c|c|c|}
\hline \multirow[t]{2}{*}{ Site of origin } & \multicolumn{2}{|c|}{$\begin{array}{l}\text { Immunohistochemistry in } \\
\text { primary tumor }\end{array}$} & \multicolumn{2}{|c|}{$\begin{array}{l}\text { Immunohistochemistry in } \\
\text { metastasis }\end{array}$} & \multirow[t]{2}{*}{ FISH (metastasis) } \\
\hline & Carcinoma & Sarcoma & Carcinoma & Sarcoma & \\
\hline Uterus & 0 & 0 & $2+$ & Not present & $\begin{array}{l}\text { HER2/CEP17 ratio 1.0, HER } 2 \text { copy number } 1.8 \text { (negative per } \\
\text { both ASCO/CAP } 2007 \text { and 2013) }\end{array}$ \\
\hline Uterus & $1+$ & Not present & 0 & $1+$ & Not done \\
\hline Uterus & $1+$ & Not present & $2+$ & 0 & $\begin{array}{l}\text { HER2/CEP17 ratio 1.3, HER } 2 \text { copy number } 2.0 \text { (negative per } \\
\text { both ASCO/CAP } 2007 \text { and 2013) }\end{array}$ \\
\hline Uterus & $3+$ & Not present & $2+$ & Not present & $\begin{array}{l}\text { HER2/CEP17 ratio 3.8, HER2 copy number } 9.1 \text { (positive per } \\
\text { both ASCO/CAP } 2007 \text { and 2013) }\end{array}$ \\
\hline Ovary & $2+$ & Not present & 0 & Not present & $\begin{array}{l}\text { HER2/CEP17 ratio } 1.9 \text {, HER } 2 \text { copy number } 6.0 \text { (equivocal per } \\
\text { ASCO/CAP 2007, and positive per ASCO/CAP 2013) } \underline{\text { HER } 2} \\
\text { FISH on primary: HER2/CEP17 ratio 1.6, HER } 2 \text { copy number } \\
\text { 4.6; negative per ASCO/CAP } 2007 \text {, and equivocal per ASCO/ } \\
\text { CAP 2013) }\end{array}$ \\
\hline
\end{tabular}


Table 6 Clinical follow-up data of uterine and ovarian carcinosarcomas

\begin{tabular}{llllll}
\hline & $\begin{array}{l}\text { Number of cases with follow-up } \\
\text { data Total }(n=79)\end{array}$ & $\begin{array}{l}\text { Follow-up (months) range } \\
\text { (median) }\end{array}$ & $\begin{array}{l}\text { Alive, no evidence of } \\
\text { disease }(n)\end{array}$ & $\begin{array}{l}\text { Alive with disease } \\
(n)\end{array}$ & $\begin{array}{l}\text { Dead of disease } \\
(n)\end{array}$ \\
\hline Uterine & HER2 positive $(n=12)$ & $9-50(24)$ & 3 & 3 & 6 \\
& HER2 negative $(n=52)$ & $2-63(21)$ & 18 & 14 & 20 \\
Ovarian & HER2 positive $(n=1)$ & 23 & 0 & 1 & 0 \\
& HER2 negative $(n=14)$ & $1-41(23)$ & 3 & 4 & 7 \\
\hline
\end{tabular}

and complete circumferential membranous staining is not required for a $3+$ immunohistochemical score, instead a "U-shaped"/basolateral or lateral staining pattern is also acceptable. Our data suggest, that the possibility of HER2 targeted therapy should be considered as a treatment option for HER2-positive gynecologic carcinosarcomas in future clinical trials.

\section{Compliance with ethical standards}

Conflict of interest The authors declare that they have no conflict of interest.

Publisher's note: Springer Nature remains neutral with regard to jurisdictional claims in published maps and institutional affiliations.

\section{References}

1. Artioli G, Wabersich J, Ludwig K, Gardiman MP, Borgato L, Garbin F. Rare uterine cancer: carcinosarcomas. Review from histology to treatment. Crit Rev Oncol Hematol. 2015;94:98-104.

2. Matsuo K, Omatsu K, Ross MS, Johnson MS, Yunokawa M, Klobocista MM, et al. Impact of adjuvant therapy on recurrence patterns in stage I uterine carcinosarcoma. Gynecol Oncol. 2017;145:78-87.

3. El-Nashar SA, Mariani A. Uterine carcinosarcoma. Clin Obstet Gynecol. 2011;54:292-304.

4. Berton-Rigaud D, Devouassoux-Shisheboran M, Ledermann JA, Leitao MM, Powell MA, Poveda A, et al. Gynecologic Cancer InterGroup (GCIG) consensus review for uterine and ovarian carcinosarcoma. Int J Gynecol Cancer. 2014;24:S55-60.

5. Garg G, Shah JP, Kumar S, Bryant CS, Munkarah A, Morris RT. Ovarian and uterine carcinosarcomas: a comparative analysis of prognostic variables and survival outcomes. Int J Gynecol Cancer. 2010;20:888-94.

6. Ferguson SE, Tornos C, Hummer A, Barakat RR, Soslow RA. Prognostic features of surgical stage I uterine carcinosarcoma. Am J Surg Pathol. 2007;31:1653-61.

7. Rauh-Hain JA, Diver EJ, Clemmer JT, Bradford LS, Clark RM, Growdon WB, et al. Carcinosarcoma of the ovary compared to papillary serous ovarian carcinoma: a SEER analysis. Gynecol Oncol. 2013;131:46-51.

8. Tanner EJ, Leitao MM Jr., Garg K, Chi DS, Sonoda Y, Gardner GJ, et al. The role of cytoreductive surgery for newly diagnosed advanced-stage uterine carcinosarcoma. Gynecol Oncol. 2011;123:548-52.

9. Sutton G, Kauderer J, Carson LF, Lentz SS, Whitney CW, Gallion $\mathrm{H}$, et al. Adjuvant ifosfamide and cisplatin in patients with completely resected stage I or II carcinosarcomas (mixed mesodermal tumors) of the uterus: a Gynecologic Oncology Group study. Gynecol Oncol. 2005;96:630-4.

10. Homesley HD, Filiaci V, Markman M, Bitterman P, Eaton L, Kilgore LC, et al. Phase III trial of ifosfamide with or without paclitaxel in advanced uterine carcinosarcoma: a Gynecologic Oncology Group Study. J Clin Oncol. 2007;25:526-31.

11. Powell MA, Filiaci VL, Hensley ML, Huang HQ, Moore KN, Tewari KS, et al. A randomized phase 3 trial of paclitaxel (P) plus carboplatin (C) versus paclitaxel plus ifosfamide (I) in chemotherapy-naive patients with stage I-IV, persistent or recurrent carcinosarcoma of the uterus or ovary: an NRG Oncology trial. J Clin Oncol. 2019;37:5500-5500.

12. Buza N, English DP, Santin AD, Hui P. Toward standard HER2 testing of endometrial serous carcinoma: 4-year experience at a large academic center and recommendations for clinical practice. Mod Pathol. 2013;26:1605-12.

13. Fader AN, Roque DM, Siegel E, Buza N, Hui P, Abdelghany O, et al. Randomized phase II trial of carboplatin-paclitaxel versus carboplatin-paclitaxel-trastuzumab in uterine serous carcinomas that overexpress human epidermal growth factor receptor $2 /$ neu. J Clin Oncol. 2018;36:2044-51.

14. Menderes G, Bonazzoli E, Bellone S, Black J, Predolini F, Pettinella F, et al. SYD985, a novel duocarmycin-based HER2-targeting antibody-drug conjugate, shows antitumor activity in uterine and ovarian carcinosarcoma with HER2/Neu expression. Clin Cancer Res. 2017;23:5836-45.

15. Nicoletti R, Lopez S, Bellone S, Cocco E, Schwab CL, Black JD, et al. T-DM1, a novel antibody-drug conjugate, is highly effective against uterine and ovarian carcinosarcomas overexpressing HER2. Clin Exp Metastas. 2015;32:29-38.

16. Schwab CL, English DP, Black J, Bellone S, Lopez S, Cocco E, et al. Neratinib shows efficacy in the treatment of HER2 amplified carcinosarcoma in vitro and in vivo. Gynecol Oncol. 2015; 139:112-7.

17. Wolff AC, Hammond ME, Schwartz JN, Hagerty KL, Allred DC, Cote RJ, et al. American Society of Clinical Oncology/College of American Pathologists guideline recommendations for human epidermal growth factor receptor 2 testing in breast cancer. Arch Pathol Lab Med. 2007;131:18-43.

18. Wolff AC, Hammond ME, Hicks DG, Dowsett M, McShane LM, Allison $\mathrm{KH}$, et al. Recommendations for human epidermal growth factor receptor 2 testing in breast cancer: American Society of Clinical Oncology/College of American Pathologists clinical practice guideline update. Arch Pathol Lab Med. 2014;138:241-56.

19. Jonson AL, Bliss RL, Truskinovsky A, Judson P, Argenta P, Carson L, et al. Clinical features and outcomes of uterine and ovarian carcinosarcoma. Gynecol Oncol. 2006;100:561-4.

20. Nemani D, Mitra N, Guo M, Lin L. Assessing the effects of lymphadenectomy and radiation therapy in patients with uterine carcinosarcoma: a SEER analysis. Gynecol Oncol. 2008; 111:82-88.

21. Brown E, Stewart M, Rye T, Al-Nafussi A, Williams AR, Bradburn $\mathrm{M}$, et al. Carcinosarcoma of the ovary: 19 years of prospective data from a single center. Cancer. 2004;100:2148-53. 
22. Gorai I, Yanagibashi T, Taki A, Udagawa K, Miyagi E, Nakazawa $\mathrm{T}$, et al. Uterine carcinosarcoma is derived from a single stem cell: an in vitro study. Int J Cancer. 1997;72:821-7.

23. Wada H, Enomoto T, Fujita M, Yoshino K, Nakashima R, Kurachi $\mathrm{H}$, et al. Molecular evidence that most but not all carcinosarcomas of the uterus are combination tumors. Cancer Res. 1997;57:5379-85.

24. Fujii H, Yoshida M, Gong ZX, Matsumoto T, Hamano Y, Fukunaga $\mathrm{M}$, et al. Frequent genetic heterogeneity in the clonal evolution of gynecological carcinosarcoma and its influence on phenotypic diversity. Cancer Res. 2000;60:114-20.

25. McCluggage WG. Uterine carcinosarcomas (malignant mixed Mullerian tumors) are metaplastic carcinomas. Int $\mathrm{J}$ Gynecol Cancer. 2002;12:687-90.

26. Han C, Altwerger G, Menderes G, Haines K, Feinberg J, Lopez S, et al. Novel targeted therapies in ovarian and uterine carcinosarcomas. Discov Med. 2018;25:309-19.

27. McConechy MK, Hoang LN, Chui MH, Senz J, Yang W, Rozenberg N, et al. In-depth molecular profiling of the biphasic components of uterine carcinosarcomas. J Pathol Clin Res. 2015;1:173-85.

28. Hembree TN, Teer JK, Hakam A, Chiappori AA. Genetic investigation of uterine carcinosarcoma: case report and cohort analysis. Cancer Control. 2016;23:61-66.

29. Growdon WB, Roussel BN, Scialabba VL, Foster R, DiasSantagata D, Iafrate AJ, et al. Tissue-specific signatures of activating PIK3CA and RAS mutations in carcinosarcomas of gynecologic origin. Gynecol Oncol. 2011;121:212-7.

30. Cherniack AD, Shen H, Walter V, Stewart C, Murray BA, Bowlby $\mathrm{R}$, et al. Integrated molecular characterization of uterine carcinosarcoma. Cancer Cell. 2017;31:411-23.

31. Zhao S, Bellone S, Lopez S, Thakral D, Schwab C, English DP, et al. Mutational landscape of uterine and ovarian carcinosarcomas implicates histone genes in epithelial-mesenchymal transition. Proc Natl Acad Sci USA. 2016;113:12238-43.

32. Amant F, Vloeberghs V, Woestenborghs H, Debiec-Rychter M, Verbist L, Moerman P, et al. ERBB-2 gene overexpression and amplification in uterine sarcomas. Gynecol Oncol. 2004; 95:583-7.

33. Livasy CA, Reading FC, Moore DT, Boggess JF, Lininger RA. EGFR expression and HER2/neu overexpression/amplification in endometrial carcinosarcoma. Gynecol Oncol. 2006;100:101-6.

34. Schipf A, Mayr D, Kirchner T, Diebold J. Molecular genetic aberrations of ovarian and uterine carcinosarcomas-a CGH and FISH study. Virchows Arch. 2008;452:259-68.

35. Raspollini MR, Susini T, Amunni G, Paglierani M, Taddei A, Marchionni M, et al. COX-2, c-KIT and HER-2/neu expression in uterine carcinosarcomas: prognostic factors or potential markers for targeted therapies? Gynecol Oncol. 2005;96:159-67.
36. Cimbaluk D, Rotmensch J, Scudiere J, Gown A, Bitterman P. Uterine carcinosarcoma: immunohistochemical studies on tissue microarrays with focus on potential therapeutic targets. Gynecol Oncol. 2007;105:138-44.

37. Sawada M, Tsuda H, Kimura M, Okamoto S, Kita T, Kasamatsu $\mathrm{T}$, et al. Different expression patterns of KIT, EGFR, and HER-2 (c-erbB-2) oncoproteins between epithelial and mesenchymal components in uterine carcinosarcoma. Cancer Sci. 2003; 94:986-91.

38. Saglam O, Husain S, Toruner G. AKT, EGFR, C-ErbB-2, and Ckit expression in uterine carcinosarcoma. Int J Gynecol Pathol. 2013;32:493-500.

39. Buza N, Roque DM, Santin AD. HER2/neu in endometrial cancer: a promising therapeutic target with diagnostic challenges. Arch Pathol Lab Med. 2014;138:343-50.

40. Woo JS, Apple SK, Sullivan PS, Rao JY, Ostrzega N, Moatamed NA. Systematic assessment of HER2/neu in gynecologic neoplasms, an institutional experience. Diagn Pathol. 2016;11:102.

41. Nofech-Mozes S, Khalifa MA, Ismiil N, Saad RS, Hanna WM, Covens A, et al. Immunophenotyping of serous carcinoma of the female genital tract. Mod Pathol. 2008;21:1147-55.

42. Karaferic A, Jovanovic D, Jelic S. Expression of HER2/neu, estrogen and progesterone receptors, CA 125 and CA19-9 on cancer cell membrane in patients with serous and mucinous carcinoma of the ovary. J BUON. 2009;14:635-9.

43. Bookman MA, Darcy KM, Clarke-Pearson D, Boothby RA, Horowitz IR. Evaluation of monoclonal humanized anti-HER2 antibody, trastuzumab, in patients with recurrent or refractory ovarian or primary peritoneal carcinoma with overexpression of HER2: a phase II trial of the Gynecologic Oncology Group. J Clin Oncol. 2003;21:283-90.

44. Ruschoff J, Hanna W, Bilous M, Hofmann M, Osamura RY, Penault-Llorca $\mathrm{F}$, et al. HER2 testing in gastric cancer: a practical approach. Mod Pathol. 2012;25:637-50.

45. Hofmann M, Stoss O, Shi D, Buttner R, van de Vijver M, Kim W, et al. Assessment of a HER2 scoring system for gastric cancer: results from a validation study. Histopathology. 2008;52:797-805.

46. Buza N, Hui P. Marked heterogeneity of HER2/NEU gene amplification in endometrial serous carcinoma. Genes Chromosomes Cancer. 2013;52:1178-86.

47. Wolff AC, Hammond MEH, Allison KH, Harvey BE, Mangu PB, Bartlett JMS, et al. Human epidermal growth factor receptor 2 testing in breast cancer: American Society of Clinical Oncology/ College of American Pathologists Clinical Practice Guideline Focused Update. Arch Pathol Lab Med. 2018;142:1364-82.

48. Halle MK, Tangen IL, Berg HF, Hoivik EA, Mauland KK, Kusonmano K, et al. HER2 expression patterns in paired primary and metastatic endometrial cancer lesions. $\mathrm{Br} \mathrm{J}$ Cancer. 2018;118:378-87. 